\title{
PEMBERDAYAAN KELOMPOK TANI DESA SAMBIREJO MELALUI PENGOLAHAN SAMPAH TERPADU GUNA PENYEDIAAN ENERGI ALTERNATIF DAN PENINGKATAN PENDAPATAN KELUARGA
}

\section{EMPOWERMENT OF FARMERS GROUP IN SAMBIREJO THROUGH INTEGRATED PROCESS OF WASTE TO ENERGY ALTERNATIVE AND IMPROVEMENT OF FAMILY INCOME}

\author{
Oleh: \\ Lusiana $^{1}$, Evi Maryanti ${ }^{1}$, Ulfasari Rafflesia ${ }^{2}$ \\ ${ }^{1}$ Jurusan Kimia, FMIPA, Universitas Bengkulu \\ ${ }^{2}$ Jurusan Matematika, FMIPA, Universitas Bengkulu \\ lusy_chem99@yahoo.com
}

\begin{abstract}
Community services activity group on empowerment of farmers group in sambirejo trhrouh integrated process of waste to energy alternative and improvement of family income have been done. This activity aims to improve the welfare of the villagers in sambirejo especially members of Amanah Farmer Group and Makmur Jaya Farmer Group through community based integrated waste. In this activity, training of garbage separation of organic and inorganic, making organic fertilizer/compost with Takakura method, making handicrafts from plastic packaging waste and biogas installation which is expected to produce alternative energy to replace LPG and firewood for daily cooking. The implementation of these activities carried out by two methods : (1) counseling and discussion about separating domestic waste, products can be made from waste, and what types of waste can be used, (2) demonstration and practice on how to make compost with Takakura method, and biogas installations on both partners. Through these activities are expected to members of the two groups of farmers, especially the women will be able to sort household waste properly and process the waste into products which has economic value that can create small-scale domestic industry that would be able to contribute to the family and the environment.
\end{abstract}

Keywords: Farmer's Group, Waste, Takakura, Plastic Pack, Economic Product

\section{PENDAHULUAN}

Desa Sambirejo merupakan salah satu desa yang terletak di Kabupaten Rejang Lebong, Provinsi Bengkulu dengan jumlah penduduk sebanyak \pm 700 kepala keluarga dan mayoritas berprofesi sebagai petani. Kondisi geografis yang terletak di kawasan perbukitan dan pegunungan menjadikan Desa Sambirejo memiliki tanah yang subur, sehingga desa ini merupakan salah satu sentral penghasil sayur dan buah di Provinsi Bengkulu. Menurut data Badan Pusat Statistik Provinsi Bengkulu, Kabupaten Rejang Lebong mampu menghasilkan sayuran sebanyak 312.728,3 ton pada tahun 2010 dengan jenis sayuran seperti kubis, tomat, kentang, bawang daun, wortel, cabe, petsai, ketimun, kangkung, terung dan bayam (BPS, 2011). 
Setiap harinya, Desa Sambirejo mampu menghasilkan sayuran sebanyak 85 ton. Sebelum di jual ke pengepul, sayur hasil panen para petani disortir atau dipilah terlebih dahulu untuk memisahkan bagian sayur yang kotor atau rusak. Adanya proses pemilahan ini menyebabkan banyaknya penimbunan sampah sisa sayuran baik di tingkat petani maupun di pengepul. Selama ini, sampah sisa sayuran ini hanya ditimbun di pekarangan rumah atau lahan pertanian saja bahkan kadangkala dibuang ke sungai. Jumlah sayur yang tidak dimanfaatkan atau dibuang bisa semakin banyak ketika para petani harus menghadapi harga jual yang sangat murah. Tingginya harga pupuk anorganik dan biaya transportasi juga merupakan faktor penyebab berkurangnya keuntungan yang didapatkan para petani.

Sampah yang dihasilkan oleh masyarakat Desa Sambirejo tidak hanya berupa sampah sisa sayuran, melainkan juga berupa plastik, kertas dan gelas/kaca yang hingga saat ini hanya dibuang atau ditimbun begitu saja, sehingga selain mengganggu pemandangan yang ada, juga menimbulkan bau yang tidak sedap dan mencemari lingkungan. Hal ini disebabkan karena minimnya informasi dan Sumber Daya Manusia (SDM) untuk mengolah sampah menjadi berbagai produk yang bermanfaat, baik untuk dikonsumsi sendiri maupun dijual. Oleh karena itu dilakukan kegiatan dengan memanfaatkan potensi lokal yang ada untuk menghasilkan produk yang dapat membantu memecahkan persoalan yang ada khususnya bagi masyarakat petani Desa Sambirejo.

Empat permasalahan utama yang dihadapi kedua mitra khususnya dan masyarakat

Desa Sambirejo umumnya tersebut akan dapat diselesaikan antara lain dengan memanfaatkan sampah rumah tangga dan hasil pertanian melalui program pengolahan sampah terpadu melalui pemilahan sampah dan penerapan prinsip 3R (Reduce, Reuse, Recycle) atau pengurangan, penggunaan kembali dan mendaur ulang sampah (Soewedo, 1983., Syafruddin, 2004). Upaya strategis yang dapat dilakukan dalam mengatasi persoalan sampah adalah dengan mendorong partisipasi masyarakat dalam pengelolaan sampah dengan melakukan reduksi sampah di sumbernya dimulai dari rumah tangga, tingkat RT, RW, dan desa. Program ini dilakukan melalui proses pemilahan/pemisahan sampah organik dan anorganik di tingkat rumah tangga, RT, RW dan desa yang kemudian diolah lebih lanjut menjadi berbagai produk seperti biogas, pupuk kompos dan aneka produk dari plastik bungkus kemasan (Wardhana, 2001).

\section{METODE PENGABDIAN}

Kegiatan pengabdian kepada masyarakat ini dilakukan dengan 4 tahap yaitu: 1) Penyampaian informasi, diskusi dan tanya jawab yang bertujuan untuk meningkatkan wawasan masyarakat tentang cara pemilahan sampah rumah tangga, produk-produk yang berasal dari sampah dan jenis sampah apa saja yang dapat digunakan. 2) Pelatihan dan pembuatan kompos dengan metode Takakura. Proses pengomposan metode ini dilakukan dengan cara memasukkan sampah organik (idealnya sampah organik tercacah) ke dalam keranjang setiap harinya dan kemudian dilakukan kontrol suhu dengan cara pengadukan dan penyiraman air. Pembuatan kompos dengan keranjang takakura ini cocok untuk rumah 
tangga yang beranggota keluarga 4-7 orang karena berukuran sekitar $40 \mathrm{~cm}$ x $25 \mathrm{~cm}$ x 70 $\mathrm{cm}$. Sampah rumah tangga yang diolah di keranjang ini maksimal 1,5 kg per hari (Giacinta, 2008). Bahan yang akan dikomposkan sebaiknya dipotong kecil ukuran $2 \mathrm{~cm}$ x $2 \mathrm{~cm}$. Semakin kecil ukuran akan semakin cepat terurai. Keranjang kemudian ditutup dengan kain dan biarkan selama 40 sampai 60 hari sambil sesekali diaduk. Proses pengomposan berjalan dengan baik apabila pada bagian luar keranjang terasa hangat. Bahan yang telah menjadi kompos akan berwarna hitam, tidak berbau dan tidak becek. 3) Pelatihan dan pembuatan aneka produk dari sampah plastik bungkus kemasan. Dalam kegiatan ini ibu-ibu anggota kelompok tani diberikan tehnik-tehnik cara membersihkan sampah plastik, pemotongan, penganyaman serta penjahitan kemasan sampah plastik sehingga menjadi aneka produk seperti dompet, tas, kotak pensil dan lain-lain. 4). Instalasi biogas yang dibuat pada masingmasing mitra dilakukan dengan teknologi anaerob dengan bahan baku berupa sampah sisa sayuran.

\section{HASIL DAN PEMBAHASAN}

Kegiatan pelatihan pembuatan kompos dan aneka produk dari sampah plastik bungkus kemasan ini dimulai dengan penyebaran selebaran yang berisi cara pembuatan kompos dengan metode Takakura yang bertujuan agar ibu-ibu mampu memahami cara pembuatan kompos terlebih dahulu sebelum praktek dilakukan. Setelah itu kemudian dilakukan demonstrasi secara langsung tentang cara membuat keranjang Takakura dengan melibatkan peran serta ibu-ibu/bapak-bapak anggota kelompok tani. Selama kegiatan penyuluhan berlangsung, mendapatkan tanggapan positif dari ibu/bapak anggota kedua kelompok tani (Gambar 1).
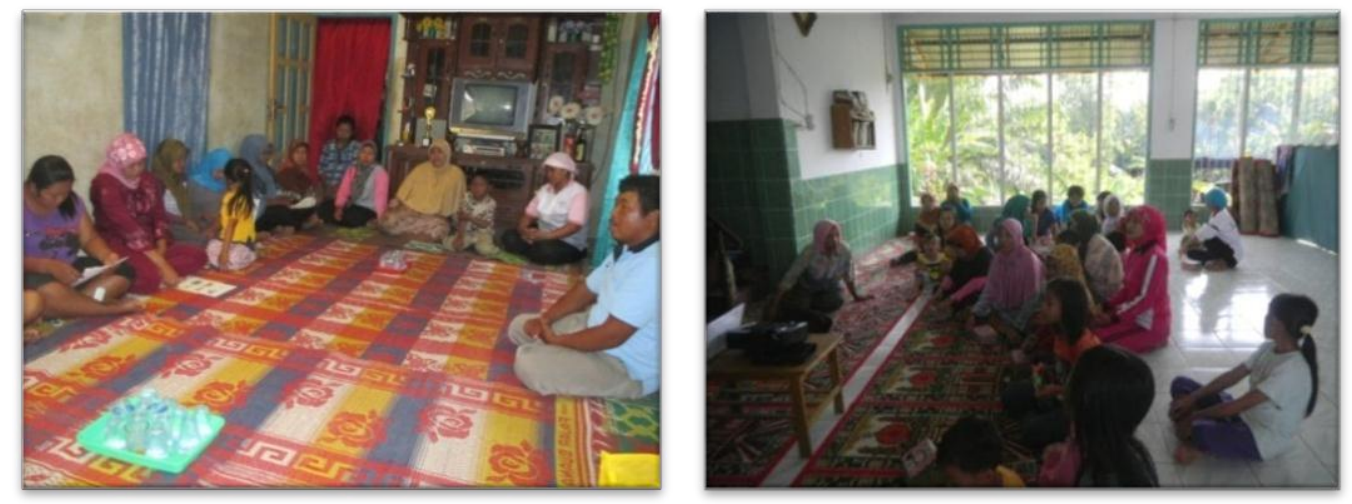

Gambar 1. Kegiatan Penyuluhan terhadap Ibu-ibu/Bapak-bapak Anggota Kelompok Tani Amanah dan Makmur Jaya

Proses pembuatan kompos Takakura sangatlah mudah, hanya saja kita harus menyiapkan starter mikroorganisme dan pembuatan bibit kompos terlebih dahulu. Langkah persiapan ini cukup dilakukan sekali saja, selanjutnya hanya melakukan pengomposan secara terus menerus. Gambar 1 menunjukan pembuatan keranjang kompos menggunakan kardus aqua, kardus diplester tegak keempat sisi bawahnya sedangkan sisi atasnya dipotong 
sedikit supaya tingginya pas dengan keranjangnya. Kardus dimasukkan ke dalam keranjang sambil ditekan supaya masuk dan pas sehingga keranjang bisa ditutup. Hal tersebut bertujuan agar material yang ada di dalam keranjang tidak berceceran keluar, serangga dari luar tidak masuk ke dalam keranjang. Satu buah bantal sekam dimasukkan di dasar keranjang. Hal ini dilakukan supaya cairan sampah dan kompos tidak merembes. Kemudian masukkan tanah dan ratakan diatas permukaan bantal sekam tersebut. Setelah permukaan rata, dimasukkan sampah organik berupa sisa sayur-sayuran dan diaduk secara merata, kemudian ditutup kembali dengan bantal sekam untuk menutup sampah yang baru dimasukan ke dalam keranjang.

Sampah dapur yang cocok dijadikan kompos Takakura adalah sisa sayuran, buahbuahan, nasi, roti, mie, kue, dan lain-lain. Proses pembuatan kompos Takakura ini berlangsung kering dan berbau, sehingga tidak terkesan jorok dan keranjang bisa ditempatkan di dapur. Proses reaksinya berlangsung secara aerobik seperti berikut:

Bahan organik $+\mathrm{O}_{2} \stackrel{\text { Mikroba aerob }}{\longrightarrow} \mathrm{H}_{2} \mathrm{O}+\mathrm{CO}_{2}+$ Hara + Humus + Energi
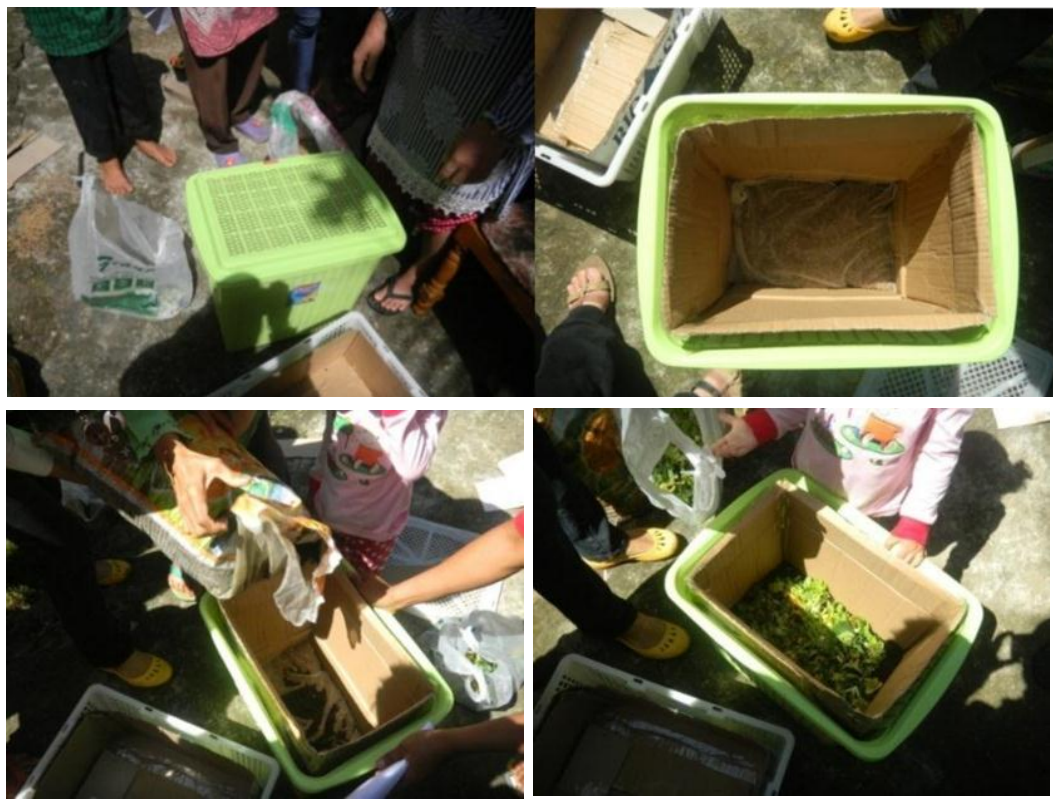

Gambar 2. Pembuatan kompos dengan metode Takakura

Pada kegiatan pelatihan pembuatan produk dari sampah plastik bungkus kemasan dilakukan dengan demonstrasi cara memotong, melipat, menganyam dan menjahit plastik bungkus kemasan menjadi produk seperti tas, dompet dan tempat laptop (Gambar 4). Langkah awal mengolah sampah plastik menjadi kerajinan adalah adalah memisahkan sampah kering dan sampah basah. Selanjutnya sampah kering seperti bungkus minuman ringan seperti kopi, susu dan mie instan dibersihkan. Setelah itu plastik-plastik yang telah dicuci dan dikeringkan kemudian dipotong-potong seperti pola barang kerajinan yang akan dibuat. Pola dibuat sesuai dengan bentuk barang yang akan dibuat. Setelah dipotong sesuai dengan pola, langkah selanjutnya adalah menjahit sesuai dengan pola tersebut. Adapun 
produk yang telah berhasil dibuat pada kegiatan ini berupa dompet, tas dan kotak pensil.
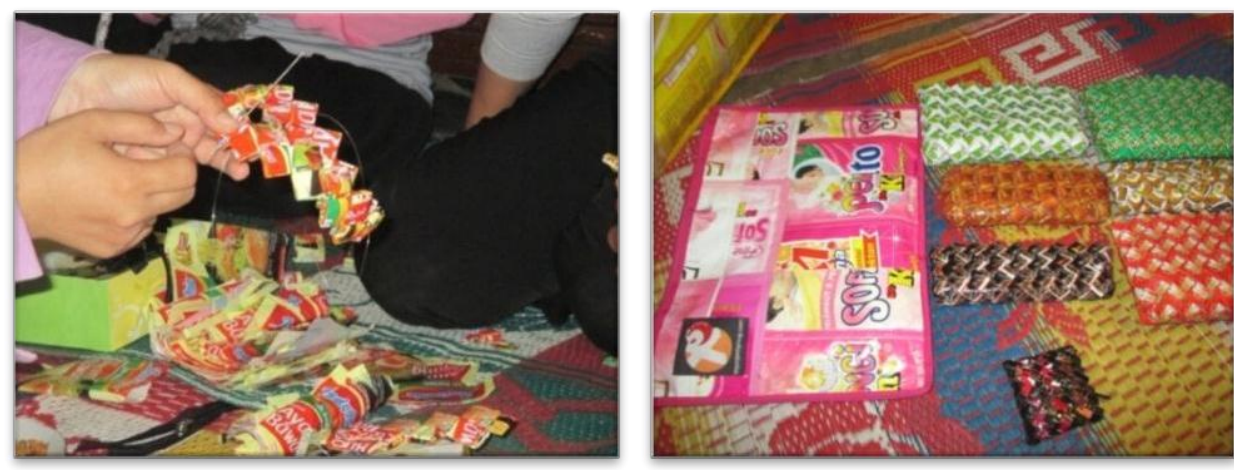

Gambar 3. Pemanfaatan limbah plastik menjadi aneka produk yang bernilai ekonomis

Untuk pembuatan instalasi biogas diawali dengan pembuatan instalasi digester, bak inlet dan outlet, pengisian sampah sisa sayuran dan proses pembentukan gas. Adapun rancangan instalasi biogas yang diterapkan pada Kelompok Tani Desa Sambirejo ditunjukkan pada Gambar 4. Digester dibuat menggunakan tangki air polietilen excel berkapasitas 1000 L. Pada bagian badan atas tangki dilubangi dan dihubungkan menggunakan pipa 4 inci ke tong plastik sebagai inlet, dan pada bagian badan bawah sebagai outlet. Tinggi feed inlet harus lebih tinggi posisinya daripada outlet. Tinggi feed outlet harus disesuaikan dengan ketinggian feed dalam digester sehingga tidak menghalangi gas keluar ke penampung gas. Pada bagian atas digester, dipasang pipa $1 / 2$ inci untuk gas keluar ke penampung gas (Gambar 5). Penampung gas yang digunakan terbuat dari plastik berukuran $0,2 \mathrm{~mm}$ dengan diameter $85 \mathrm{~cm}$ dan panjang $2,5 \mathrm{~m}$.

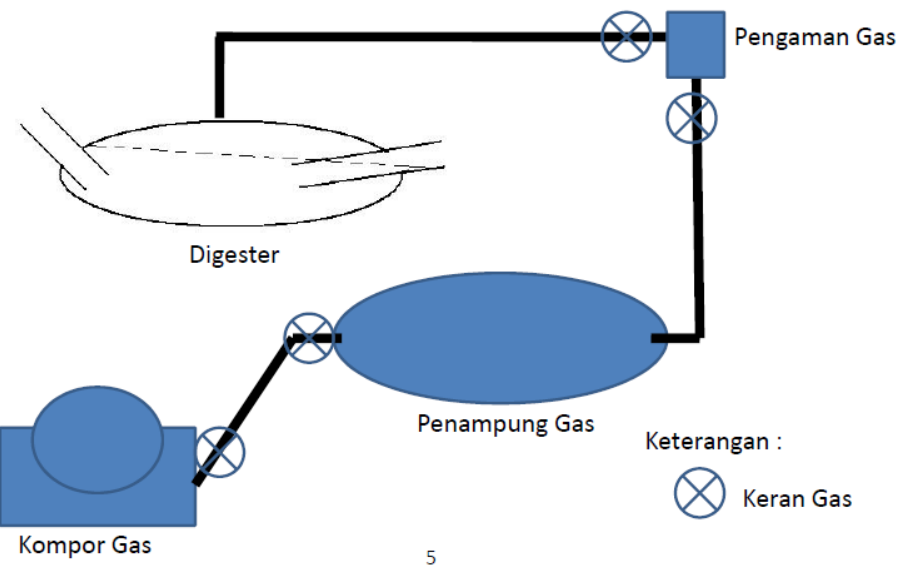

Gambar 4. Rancangan instalasi biogas yang diterapkan (Abrar, A., 2011) 


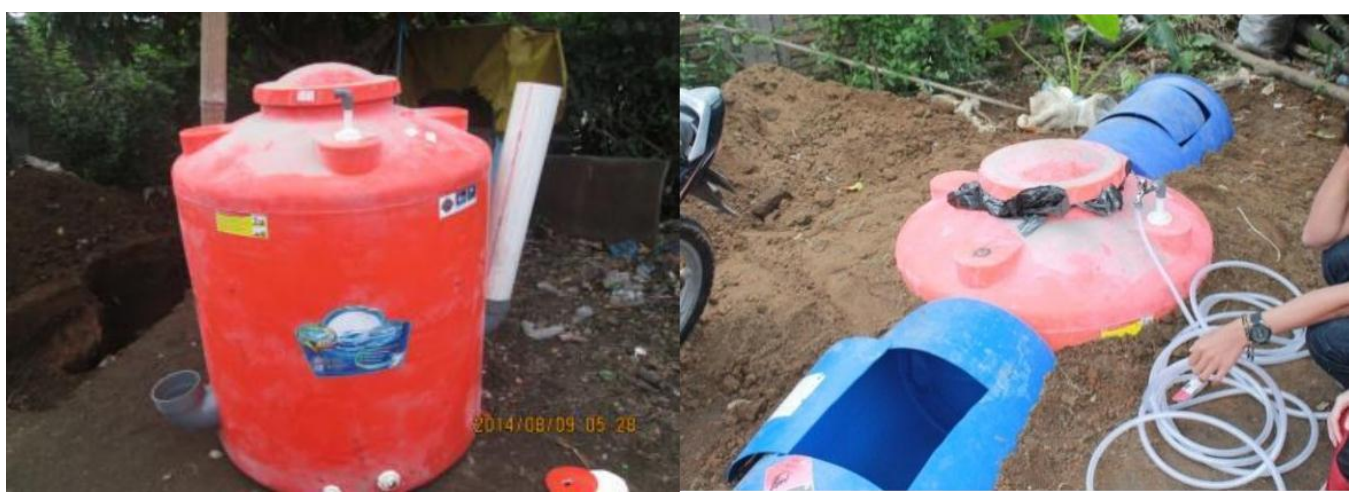

Gambar 5. Bentuk digester yang diterapkan pada kedua mitra

Setelah pembuatan digester selesai dilakukan perakitan tungku kompor yang akan digunakan. Kompor 1 tungku yang digunakan adalah kompor komersil yang dijual dipasaran. Tetapi sebelum digunakan pada instalasi biogas, spuyer kompor gas harus dibuka, dikarenakan tekanan biogas khususnya berbahan baku sampah organik ini bertekanan rendah sehingga tidak mampu memompa gas ke burner. Selang yang digunakan sebagai penghubung dari digester ke tungku kompor adalah selang plastik berdiamater $1 / 2$ inci.

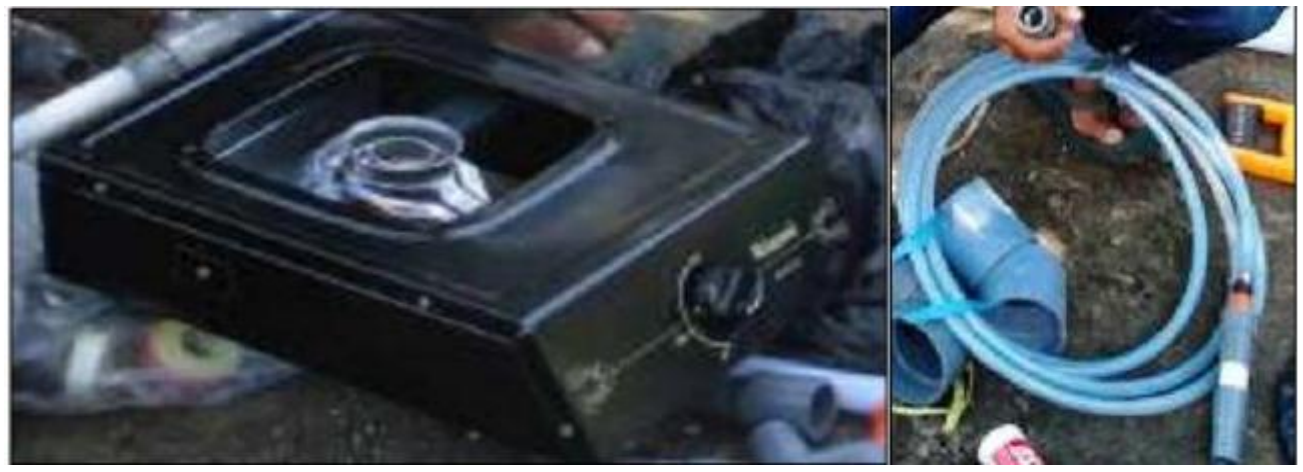

Gambar 6. Kompor gas dan selang untuk kompor gas

Setelah semua instalasi biogas dirakit, dilanjutkan dengan pemasangan instalasi biogas pada lokasi kedua mitra. Lokasi dipilih berdasarkan hasil kesepakatan dari seluruh anggota kelompok tani. Pertama-tama dilakukan penanaman tabung digester sedalam $\pm 1,5$ meter. Digester ditanam dalam tanah dengan tujuan menghindari kebocoran dan lebih aman (Gambar 7).
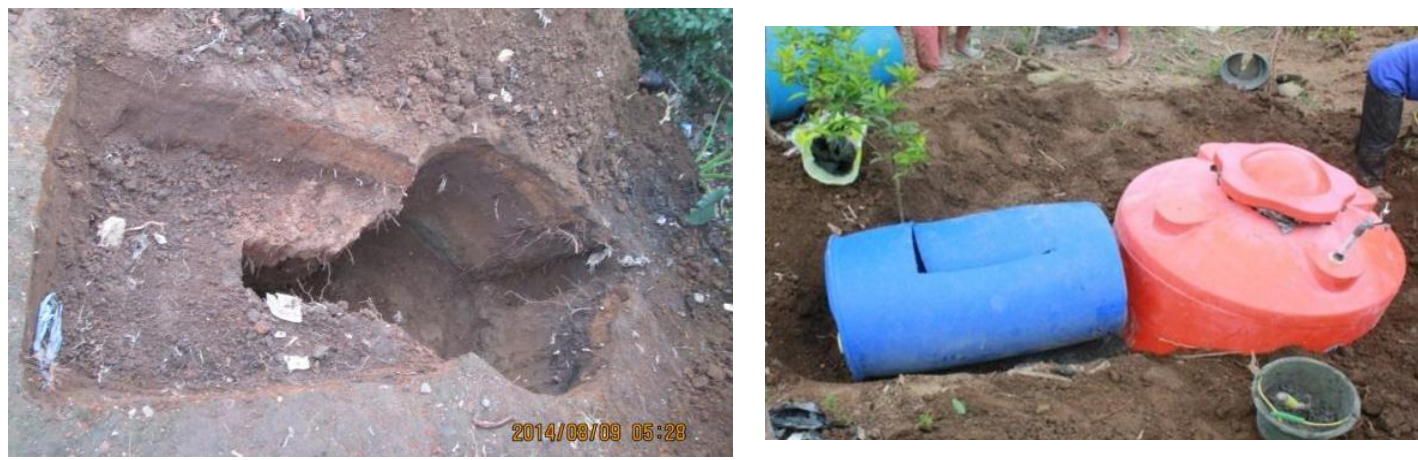

Gambar 7. Lubang dan digester yang ditanam 
Setelah instalasi digester terpasang, dilanjutkan dengan pengisian air dan sampah sisa sayuran yang telah dicacah pada tabung inlet. Air yang diisi harus mampu menenggelamkan sampah sisa sayuran (Gambar 8). Untuk mempercepat proses pembusukan sayuran, ke dalam digester juga dimasukkan kotoran sapi sebanyak 2 ember dan mikroorganisme cair sebanyak 1 liter. Proses pembusukan sampah dan pembentukan gas memakan waktu selama \pm 40 hari. Pada tabung digester tidak boleh masuk cairan yang mengandung bahan kimia seperti air sabun atau detergen karena akan mengurangi bahkan menghentikan pembentukan gas. Terbentuknya gas bisa ditandai dengan adanya gelembung gas pada plastik penampung gas.
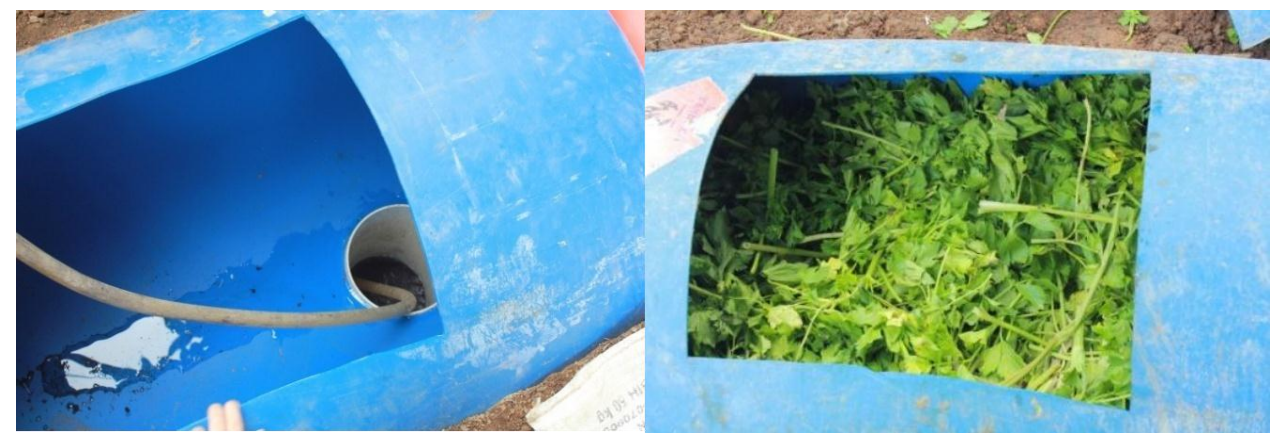

Gambar 8. Proses pengisian air dan sampah sisa sayuran ke dalam digester

Pada hari ke 28 telah terbentuk gas yang terlihat dengan menggelembungnya plastik penampung gas (Gambar 9a). Hal ini lebih cepat dari yang diperkirakan dikarenakan sampah sisa sayuran yang dimasukkan berstektur lembut dan mengandung gas seperti seledri dan kol. Gas yang dihasilkan ini sudah dapat digunakan dengan lama pemakaian $\pm 2,5 \mathrm{jam}$. Gas yang dihasilkan berwarna biru sama halnya dengan menggunakan gas elpigi (Gambar 9b). Gas ini telah dapat dimanfaatkan oleh petani untuk keperluan memasak seperti memasak air, menggoreng dan menumis sayuran. Setelah gas terbentuk, dilakukan penambahan sampah sayuran setiap hari sebanyak $\pm 50 \mathrm{Kg}$. Gas akan terbentuk kembali setelah dibiarkan selama 7 -10 hari.

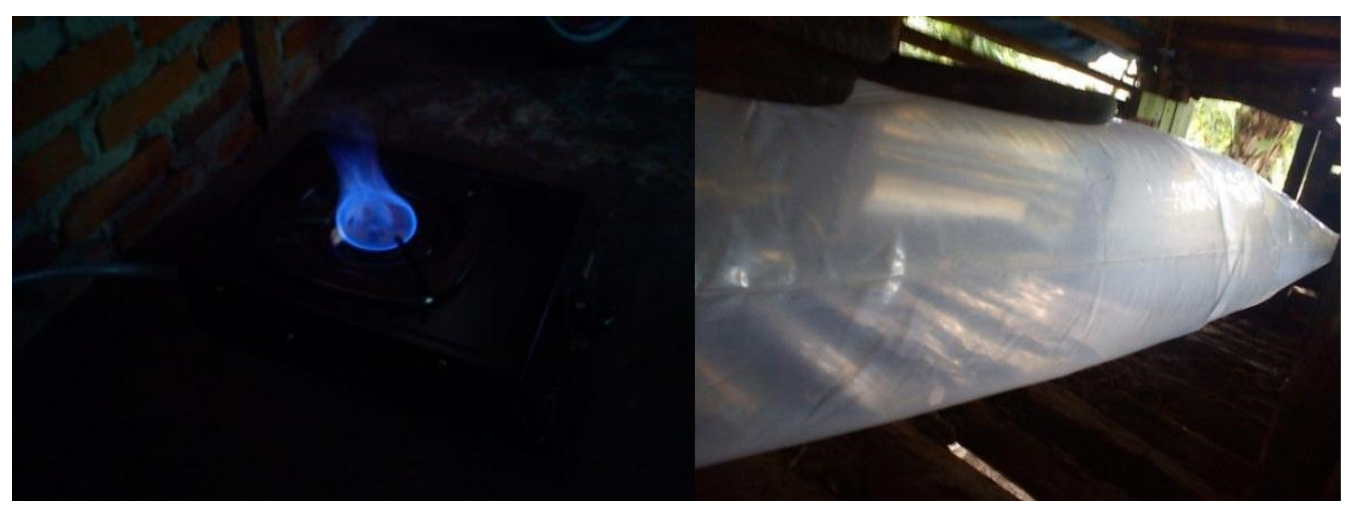

(a)

(b)

Gambar 9. Hasil instalasi biogas. (a) Penampung gas yang sudah terisi gas,

(b) gas yang dihasilkan 
Hasil kegiatan pengabdian ini memberikan manfaat yang besar bagi kedua mitra, dimana kedua mitra telah memiliki pengetahuan tentang cara memilah sampah organik dan anorganik, memanfaatkan sampah organik menjadi kompos dan biogas sedangkan sampah plastik bumgkus kemasan menjadi berbagai produk. Kompos yang dihasilkan telah digunakan untuk keperluan menanam sayur atau bunga dipekarangan rumah. Gas yang dihasilkan telah dimanfaatkan untuk keperluan memasak sehari-hari sedangkan produk sampah plastik bungkus kemasan digunakan sendiri dan menjadi ide untuk dikembangkan menjadi home industry dilingkungan kelompok tani Amanah dan Makmur Jaya.

\section{KESIMPULAN DAN SARAN}

\section{Kesimpulan}

Dari kegiatan pengabdian masyarakat yang telah dilakukan mulai dari penyuluhan sampai ke praktek (pelatihan dapat disimpulkan sebagai berikut :

1. Penyuluhan dan pelatihan berjalan lancar, ibu-ibu anggota Kelompok Tani terlihat antusias dan menerima dengan baik materi pengabdian.

2. Respon positif ibu-ibu dapat terlihat aktif bertanya dan mengajak berdiskusi pada saat penyuluhan dan praktek.

3. Keranjang Takakura telah mampu menghasilkan kompos organik

4. Ibu-ibu telah mampu membuat produk dari sampah plastik bungkus kemasan seperti dompet, tas, kotak pensil, dan bando.

5. Instalasi biogas dengan kapasitas $1000 \mathrm{~L}$ berbahan baku sampah sisa sayuran telah dapat menghasilkan biogas dengan lama pemakaian $\pm 2,5$ jam dan akan terisi kembali setelah dibiarkan selama 7-10 hari

\section{Saran}

Untuk memperoleh manfaat yang maksimal dari kegiatan ini perlu adanya kegiatan berkelanjutan, untuk itu disarankan:

1. Pembinaan yang intensif bagi ibu-ibu anggota Kelompok Tani Amanah dan Makmur Jaya untuk kepentingan pengembangan teknologi yang utuh maupun dari aspek pemasaran.

2. Perlu dibentuk kelompok industri rumah tangga untuk memudahkan dalam pengembangan usaha, dan perlu bekerja sama dengan pihak penyedia modal untuk permodalan anggota Kelompok Tani sehingga dapat mengembangkan usaha yang lebih komersil dan produk hasil pembuatan kompos serta produk kerajinan limbah plastik tersebut dapat menjadi sumber pendapatan bagi anggota Kelompok Tani khususnya para ibu-ibu. 


\section{UCAPAN TERIMAKASIH}

Penulis mengucapkan terimakasih yang sebesar-besarnya kepada DITLITABMAS DIKTI yang telah memberikan bantuan dana melalui Hibah Pengabdian Masyarakat IbM Tahun 2014 sehingga kegiatan pengabdian ini dapat terlaksana, penulis juga mengucapkan terimaksih kepada Ketua dan Anggota Kelompok Tani Amanah dan Makmur Jaya serta Kepala Desa Sambirejo, Kecamatan Selupu Rejang, Kabupaten Rejang Lebong atas kerjasamanya sehingga kegiatan ini dapat berjalan dengan lancar.

\section{DAFTAR PUSTAKA}

Giacinta, 2008, Pembuatan Kompos dari Sampah Rumah Tangga, http://www.kebonkembang.com/panduan-dan-tip-rubrik-35/221.html.

Hadi, Sudharto P., 2005, Demensi Lingkungan Perencanaan Pembangunan, Gadjah Mada University Press, Yogyakarta.

Hadiwiyoto, Soewedo, 1983, Penanganan dan Pemanfaatan Sampah, Yayasan Idayu, Jakarta.

Kompas, 13 Agusrus 2003, Sampah, Cermin Wajah Perkotaan, diakses dari http://www.kompas.com, pada tanggal 27 Maret 2014.

Kompas, 10 Januari 2004, Sampah dan Pemerintah, diakses dari http://www.kompas.com, pada tanggal 27 Maret 2014.

Syafrudin, CES, Ir. MT, 2004, Model Pengelolaan Sampah Berbasis Masyarakat (Kajian Awal Untuk Kasus Kota Semarang), Makalah pada Diskusi Interaktif: Pengelolaan Sampah Perkotaan Secara Terpadu, Program Magister Ilmu Lingkungan UNDIP.

Tuti Kustiah, 2005, Kajian Kebijakan Pengelolaan Sanitasi Berbasis Masyarakat, Pusat Penelitian dan Pengembangan Permukiman, Badan Penelitian dan Pengembangan Departemen Pekerjaan Umum, Bandung.

Wardhana, Wisnu Arya, 2001, Dampak Pencemaran Lingkungan (Edisi Revisi), Penerbit ahun Pertama. 